\title{
Erratum to: Consumer Electric Energy Management Strategies and Preferences in Emergency Demand Response: Results from a Survey
}

Huiyang Li, Haya Salah and Ziang Zhang

\author{
Erratum to: \\ "Consumer Electric Energy Management Strategies \\ and Preferences in Emergency Demand Response: \\ Results from a Survey" in: S.M. Cetiner et al. (eds.), \\ Advances in Human Factors in Energy: Oil, Gas, \\ Nuclear and Electric Power Industries, Advances \\ in Intelligent Systems and Computing 495, \\ DOI 10.1007/978-3-319-41950-3_8
}

The book was inadvertently published with an incorrect last name for the chapter author as Salah1 instead of Salah. The erratum book and the chapter has been updated with the changes.

The updated original online version for this chapter can be found at DOI 10.1007/978-3-319-41950-3_8

H. Li $(\bowtie) \cdot$ H. Salah $\cdot$ Z. Zhang

State University of New York at Binghamton, Binghamton, NY, USA

e-mail: hli@binghamton.edu

H. Salah

e-mail: hsalah1@ binghamton.edu

Z. Zhang

e-mail: zhangzia@binghamton.edu 